\title{
Dendrochronological insights into past oak growth
}

\author{
JR Pilcher \\ Palaeoecology Centre, Queens University of Belfast, Belfast, Northern Ireland, UK
}

(Received 31 October 1994; accepted 31 October 1995)

\begin{abstract}
Summary - European tree-ring research on deciduous oak species has been developed, in most centres, for archaeological and historic building dating. Studies of living trees have been carried out to anchor the modern end of long chronologies of historical, archaeological and sub-fossil timbers. Chronologies in Ireland, England and Germany extend for 7000-8 000 years from the present. Once the tree-ring chronologies are completed, every annual ring in every piece of wood that forms the chronology can be precisely assigned to the year in which it grew. Any environmental information extracted from the timbers is thus exactly dated. This enables us to look at the effects of specific events on oaks in different regions. Information is preserved in the trees on four different time or frequency ranges.
\end{abstract}

dendrochronology / deciduous oak / Europe / Ireland / France

Résumé - Aperçu de la croissance passée des chênes sur la base d'analyses dendrochronologiques. L'analyse dendrochronologique des chênes européens a été développée dans beaucoup de cas pour permettre la datation de monuments archéologiques ou historiques. Des études sur des arbres vivants ont été menées pour définir l'extrémité actuelle de séries chronologiques longues obtenues sur des bois de la période historique, préhistorique, voire sub-fossile. Les séries chronologiques obtenues en Irlande, en Allemagne et en Angleterre s'étendent sur une période de 7000 à 8000 ans. Une fois ces séries chronologiques bien établies, il est possible de préciser pour chaque cerne annuel de n'importe quel fragment de bois l'année de sa formation. Les informations sur l'environnement pouvant être déduites de ces bois sont ainsi datées avec beaucoup de précision. Cela nous permet d'observer les effets d'événements précis sur les chênes de régions parfois éloignées les unes des autres. L'information correspondante est conservée dans les arbres à trois échelles de temps ou de fréquences : événements accidentels se produisant lors d'une année, effets à moyen terme correspondant par exemple à des séries d'éruption volcaniques, et dérives à long terme dans les dynamiques de croissance, liées aux changements climatiques.

dendrochronologie / chênes décidus / Europe / Irlande / France 


\section{INTRODUCTION}

Dendrochronology had its origins in the work of Douglass in the early years of this century in the arid southwest United States (Robinson, 1990). Douglass was studying the relationship between sunspots and rainfall and needed a way of extending the short rainfall record in his area. As the main limiting factor on tree growth in the area was rainfall, the tree-ring widths provided him with a record of past rainfall. This record came with the exact time scale and annual resolution provided by the annual growth rings of the trees. When Douglass lectured on his work to the Carnegie Institute in 1914, the implications of his work for archaeological dating were realised and dendrochronology became the premier dating method for archaeological ruins in the southewest United States. The archaeological application of Douglass's work led to the creation of the Laboratory of Tree-Ring Research at the University of Arizona in Tucson in 1937 and to the spread of dendrochronology as a dating method all over the temperate world. When the tree-ring method was brought to Europe by Huber in the early 1940 s (Eckstein and Pilcher, 1990), it was apparent that there was no simple relationship between the climate and the ring widths in the more temperate European climates, yet the process of cross-dating whereby the pattern of wide and narrow rings was matched from sample to sample, was as strong as in the southwest United States. In Europe, different laboratory techniques were developed that were more appropriate to the analysis of oak rather than coniferous species (Pilcher, 1990), but the essential tree-ring methods of visual cross-dating and replication remained fundamental to the method. Recently some laboratories have attempted to dispense with the traditional visual cross-dating check and to rely entirely on computer correlations. Long experience suggests that this will eventu- ally allow errors to accumulate and may lead to false datings (Hillam et al, 1987).

Most of the early dendrochronology in Europe used oak species. Oak is the commonest building timber before the 18th century except in alpine regions (Hollstein, 1980; Baillie, 1982; Schweingruber, 1993). It is also the most abundantly preserved archaeological and sub-fossil timber in most regions (Baillie, 1982; Pilcher et al, 1984; Leuschner et al, 1987; Becker, 1993). European dendrochronology developed first in Germany and then Ireland, with more recent centres in most countries of Europe. However, almost all these laboratories concentrated on either climate reconstruction or on archaeological dating. To use the existing data for the purposes of forest ecology we must take account of the fact that these data were produced with different site and sample selection criteria than might be used for an ecological study. In particular, trees showing signs of decline or decay would normally be avoided with a selection made for the healthy, elite trees.

The examples I will use are from France and Ireland, but similar inferences could be made using tree rings from other areas. The chronologies I will mention are available from the International Tree-Data Bank at the World Data Center A for Paleoclimatology in Boulder, CO. The data bank holds the site details and all the ring-width measurements of individual trees.

\section{THE TREE-RING CHRONOLOGY}

The essence of dendrochronology is replication. Except in special circumstances, the dendrochronologist will average the growth of a number of trees to form a chronology. First the patterns of individual trees are synchronised by cross-dating. This is the matching of the patterns of wide and narrow rings. This matching can be by eye on the wood, by eye using plotted graphs of ring widths or 
by computer correlation. The dendrochronologist is not interested in the absolute width of the rings, but in whether they are wider or narrower than the previous year. To calculate a numerical estimate of the cross-dating strength it is usual to first filter the tree-ring series by expressing each ring width as a percentage of the widths of the five rings of which it is the central value (Baillie and Pilcher, 1973). This has two effects: it removes all but the highest frequency changes and also renders the ring widths of both wide- and narrow-ringed trees to a mean value of 100 . It is now possible to calculate a correlation coefficient between the two series. The high frequency variation that the cross-dating tests is the first type of information available to the forest ecologist. It tells us whether the tree is growing better or worse than in the previous year. Because of the strength of this annual signal and the distances over which it can be traced, we know that the main driving force is climatic.

Figure 1 shows cross-dating from tree to tree within one forest (forêt de Fontainebleau). The dendrochronologist would normally take the ring-patterns of 10-20 or more trees and average them to form a site chronology. There are various processes known as indexing that may be used to bring the ring widths of each tree to a standard value of 100 units before aver- aging. This prevents the average being biased by the ring widths of fast growing trees. Some of the curve-fitting techniques that are used for indexing ring widths are also designed to remove the natural growth trend of the tree. In conifers, this growth trend is usually in the form of a negative exponential, but in oak the ring widths tend to remain much more constant through the life of the tree. When the index series for a number of trees are averaged, the signal (that is, the information common to all the trees) is strengthened and the anomalies of individual trees are averaged out. Figure 2 shows two chronologies from different forests in northern France (Fontainebleau and Tronçais). Although these forests are ca $225 \mathrm{~km}$ apart, the patterns in the chronologies are very similar; notice, for example, the narrow rings in 1870 and 1874 which at both sites were among the narrowest rings of the century. The similarity of the patterns over long distances helps the archaeologist to date timbers that come from outside the region in which the chronologies have been constructed. Some regions like northern and central France are fairly homogeneous, but areas such as Brittany, which has a strong climatic gradient from east to west, also have a strong gradient in tree rings. Tree-ring patterns from the SaintBrieuc region of Brittany are more similar to
Fig 1. Ring widths from three trees from the nature reserve at forêt de Fontainebleau $\left(48^{\circ} 27^{\prime} \mathrm{N}\right.$, $2^{\circ} 41^{\prime} \mathrm{E}$ ), parcelle 275 . The difference in absolute ring width between the trees does not hinder the process of cross-dating as this is only concerned with relative changes from year to year.

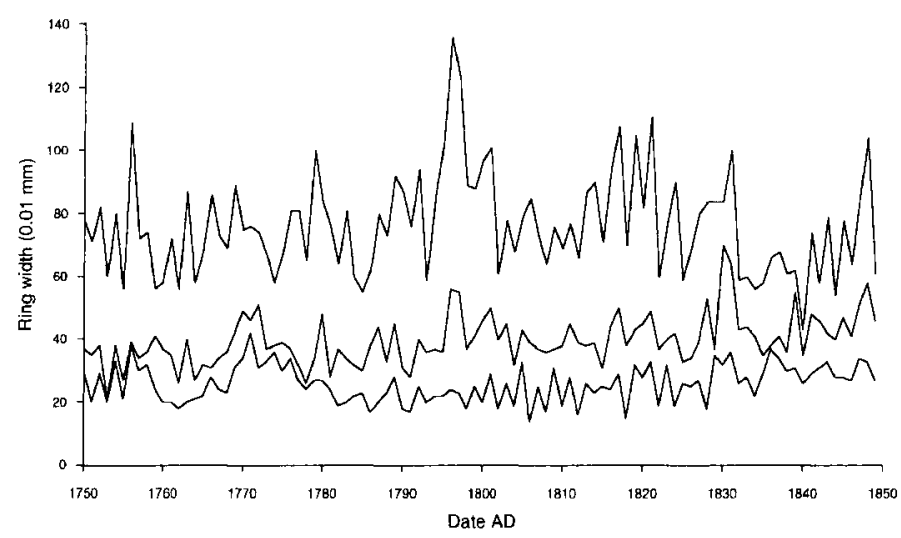




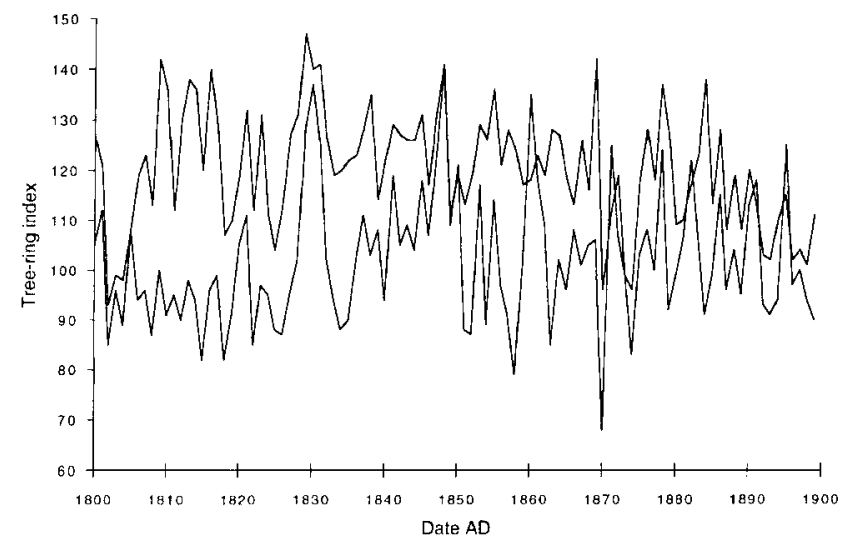

Fig 2. Index chronologies from two sites in northern France. Fontainebleau (see fig 1) (upper curve) and forêt de Tronçais $\left(46^{\circ} 40^{\prime} \mathrm{N}, 2^{\circ} 20^{\prime} \mathrm{E}\right)$ (lower curve). In each case the ring widths from the individual trees were standardised by fitting a simple polynomial curve to the ring width measurements. Each ring width was then expressed as a percentage of the polynomial curve for that year. The standardised measurements for all the trees are averaged for each year to produce the chronology.

those from the south of England than they are to those from the areas east of Rennes (Guibal, 1987).

\section{RECORDING OF SINGLE YEAR EVENTS IN THE TREE RINGS}

Because each ring in a tree-ring chronology is precisely dated, we can compare the response of trees in different areas to a par-

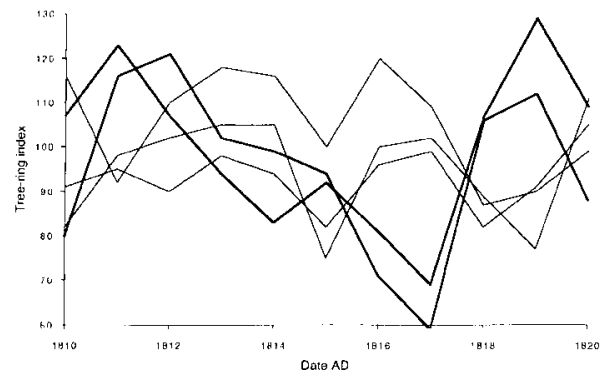

Fig 3. Three tree ring chronologies from France (Fontainebleau, Tronçais and Chambord $\left.\left[47^{\circ} 34^{\prime} \mathrm{N}, 1^{\circ} 30^{\prime} \mathrm{E}\right]\right)$ shown by thin lines and two from Ireland (Belfast area chronology and Castlecoole [ $\left.\left.54^{\circ} 20^{\prime} \mathrm{N}, 7^{\circ} 36^{\prime} \mathrm{W}\right]\right)$ shown by thick lines, showing differing responses in the two areas to the climatic deterioration following the Tambora eruption in November 1815. ticular climatic event. Let us take as an example the year 1816. This year followed the huge eruption of the volcano Tambora in Indonesia in November of 1815. From all over Europe there are records of a cold and wet summer with common crop failures. In England, 1816 was called "the year without a summer" (Bradley and Jones, 1992). In figure 3 , three chronologies from France and two from Ireland are plotted. Each of the French chronologies shows an increase in 1816. The three forests are all on dry sandy soils and the trees are thought to be limited by lack of growing season moisture. The Irish sites on the other hand show a decrease in growth which continues into 1817 . These sites are in a high rainfall area and are limited by low summer temperatures. The cold wet conditions favoured the trees in France but were detrimental to the trees in Ireland. In each case the trees sampled were mature in 1816 , but the French examples are from trees that were up to 300 years old at the time whereas the Irish trees were about 100 years. Figure 4 shows a longer section of the same chronologies and shows events around the time of the famine in Ireland. The anomaly in 1833-1835 shows a large increase in tree growth in Ireland and a decrease in France 


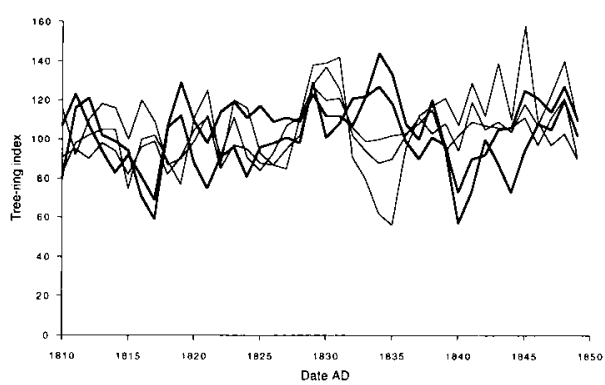

Fig 4. The same five tree ring chronologies as shown in figure 3 extended to show the time around the famine in Ireland. The low growth rates of oak in Ireland around 1840 occurred at a time of the common crop failures that came in the years preceding the outbreak of potato blight and the main famine of 1843 .

probably indicating dry conditions in Europe, followed by the decrease in growth of Irish trees down to the low of 1840. Poor conditions for oak growth were also poor conditions for crops and the 2 years of crop failures in the years before the outbreak of potato blight in 1843 were a major contributing factor in the famine disaster.

\section{MEDIUM-TERM TRENDS IN TREE GROWTH}

So far all the changes we have been looking at are high frequency changes. Let us now see what happens if we smooth out the high frequency changes. When we look at individual trees we see that much of the low frequency variation is individual to each tree. We believe that this detail is influenced by changes in the surrounding tree canopy, the death of neighbours, effects of selective felling, etc. However, when we average a number of trees we start to see more consistent details. Figure 5 shows smoothed tree-ring indices from three French sites. In particular we can see favourable conditions for oak growth in the 1850s and a consistent

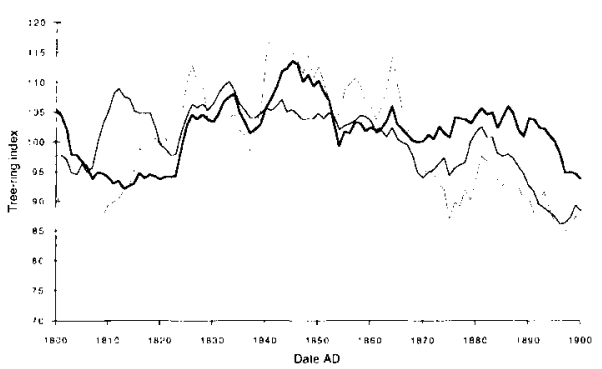

Fig 5. Three chronologies from Fontainebleau (thick line), Tronçais (medium line) and Chambord (thin line) smoothed by an 11-point moving average to show medium term trends. Many of the trends are common to all three chronologies. Note in particular the decline from 1880 to 1900.

decline from 1880 to 1900 . We can see similar consistent changes in sub-fossil trees from the third millennium $B C$ in Northern Ireland (Pilcher and Munro, 1987). These medium-term changes have not been much studied.

One interesting example of medium-term changes in tree growth rate are the growth depletions that have been studied by Baillie and Munro (1988) and Baillie (1991). These depletions are related by the coincidence of date to major volcanic eruptions. Examples are the eruption of Santorini (Thera) in 1628 BC (Baillie, 1990) and the depletion in growth in $1159 \mathrm{BC}$ that is attributed to the Icelandic eruption of Hekla. These were events on a grand scale with effects seen from Ireland to the White Mountains of California. Further evidence to link the events to volcanic eruptions comes from the acidity found in Greenland ice cores (Hammer et al, 1990). The date estimates for the acidity in the ice cores comes very close to the dates for the narrow growth rings seen in the Irish trees and to the frost damage seen in the trees from the White Mountains in California (LaMarche and Hirschboeck, 1984). The reason why the effect of these eruptions appears different in the Irish subfossil oaks from the single year events 
induced by Tambora (above) is thought to be due to the location of the sub-fossil trees on periodically waterlogged fen surfaces. Under these extreme conditions, it is likely that root damage may have resulted from one or two very wet summers. This damage would impair the growth of the tree for a number of years. However, as Baillie (1990) points out, other explanations are possible.

\section{LONG-TERM CHANGES SEEN BY DENDROCHRONOLOGY}

It is normally not possible to see growth variations that take place over longer times than the average age of the trees. However, some interesting inferences can be made from the abundance of trees preserved from the past. The samples that have been used to build the long sub-fossil chronologies were not specially selected and are a reasonably random sample of what was preserved. The distribution is far from uniform. If we examine the distribution of oaks from the river gravels of the German rivers we see episodic preservation that is interpreted as evidence for periods when the rivers were flooding frequently and eroding the treecovered river banks (Becker, 1978). The distribution of bog oaks in Ireland is also not uniform. In this case we believe that the distribution reflects the relative dryness of the fens on which the oaks grew. Figure 6 shows the distribution of bog oaks through the first to sixth millennia BC. As shown by Pilcher et al (1995), the distribution of bog oaks is also reflected in the distribution of bog pines and in the distribution of both oaks and pines from lake margins. The combination of this evidence strongly suggests that bog oak frequency is related to periods of dryness leading to dry bog surfaces and low lake water levels.

When the abundance of trees in the $A D$ era is examined we also find a very non-

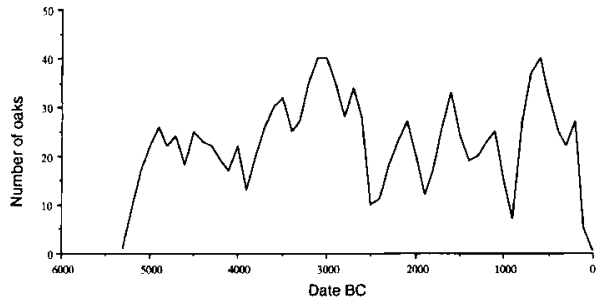

Fig 6. Number of trees in each 20-year section of the $B C$ part of the Belfast long chronology. The curve shows considerable variability in the abundance of oaks through time. The abundance is interpreted as a measure of the dryness of the fenlands on which the oaks were growing.

uniform distribution through time. In this time span we are dealing almost entirely with archaeological and historic building timbers. Here, the distribution appears to be strongly linked to the history of Europe (Baillie, 1993).

\section{HUMAN EFFECTS ON FORESTS SEEN IN TREE RINGS}

At its most simple level, the effects on individual trees are clearly recorded. The most dramatic effects are due to pollarding, shredding and other direct damage to the trees. The shredding that is common in the area around Rennes leaves a clear signature in the wood and this can be seen in historic building timbers from this region (Guibal, 1987). Figure 7 shows part of the ring pattern from a tree that has had the branches removed many times during its life. The pattern imposed by the shredding is so strong that such trees are normally useless for dendrochronology. Nevertheless, they still tell a social and historical story of woodland management.

The long-term variation of tree growth that might be expected from global warming and that might already be happening can only be reliably investigated by using the long record of tree growth that den- 


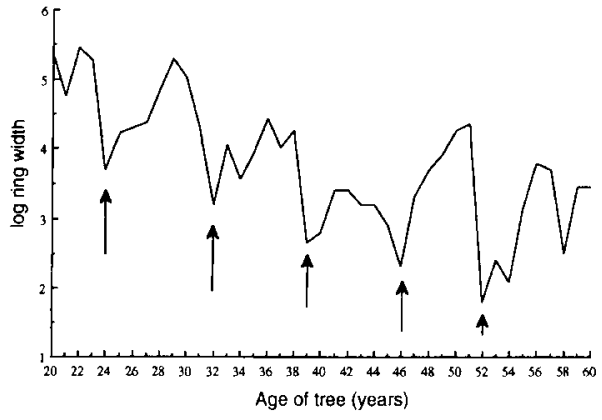

Fig 7. Part of the ring pattern from a hedgerow tree from near Rennes. The ring widths are plotted on a log scale to accentuate the periods of damage. The shredding of branches occurred every 6 or 7 years (marked by arrows)

drochronology makes possible. Evidence of increased growth due to higher partial pressures of $\mathrm{CO}_{2}$, independent of any climate change, has been claimed for bristlecone pine trees at high altitude in the White Mountains of California (LaMarche et al, 1984) and has also been shown for several species in northeast France (Becker et al, 1994a, b). Such effects may be a significant factor in estimates of tree growth into the next century. The standardisation used in most tree-ring studies would mask most of the predicted effects of $\mathrm{CO}_{2}$ changes at low altitude.

The many types of information preserved in tree rings highlights the importance of those few areas in the world where really old trees do survive, such as the bristlecone pine forests and the giant redwoods in $\mathrm{Cal}$ ifornia, and the magnificent ancient oak forests of Europe.

\section{CONCLUSION}

The techniques of dendrochronology have a lot to offer for the study of forest history, woodland management and variability in tree growth. By using the tree-ring record from historic building timbers and archaeological sites, it is possible to extend the record beyond the life span of individual trees and take advantage of the long record and the exact calendrical scale that tree rings provide. These long records allow us to see in perspective the changes that take place on the scale of human lifetimes.

\section{REFERENCES}

Baillie MGL (1982) Tree-Ring Dating and Archaeology. The University of Chicago Press, Chicago, IL

Baillie MGL (1990) Irish tree rings and an event in 1628 BC. In: Thera and the Aegean World III, Volume 3: Chronology (DA Hardt, AC Renfrew, eds), London, The Thera Foundation, 160-166

Baillie MGL (1991) Marking in marker dates - towards an archaeology with historical precision. World Archaeology $23,233-243$

Baillie MGL (1993) Archaeological wood in Ulster. Archaeomaterials 7, 139-150

Baillie MGL, Pilcher JR (1973) A simple cross-dating program for tree-ring research. Tree-Ring Bull 33 , 7-14

Baillie MGL, Munro MAR (1988) Irish tree rings, Santorini and volcanic dust veils. Nature (Lond) 332 , 344-346

Becker B (1978) Dendrochronological evidence for Holocene changes in the drainage system of southern central Europe. In: Dendrochronology in Europe (J Fletcher, ed), British Archaeological Reports International Series, 289-290

Becker B (1993) An 11 000-year German oak and pine dendrochronology for radiocarbon calibration. Radiocarbon 35, 201-213

Becker M, Nieminen TM, Geremia F (1994a) Short-term variations and long-term changes in oak productivity in northeastern France. The role of climate and atmospheric $\mathrm{CO}_{2}$. Ann Sci For 51, 477-492

Becker M, Bert GD, Bouchon J, Picard JF, Ulrich E (1994b) Tendances à long terme observees dans la croissance de divers feuillus et résineux du nordest de la France depuis le milieu du XIXe siècle. Rev For Fr 46, 335-341

Bradley RS, Jones PD (eds) (1992) Climate since AD 1500. Routledge, London

Eckstein D, Pilcher JR (1990) Dendrochronology in western Europe. In: Methods of Dendrochronology: Applications in the Environmental Sciences (LA Kairiukstis, ER Cook, eds), International Institute for Applied Systems Analysis, Kluwer Academic Publishers, Boston, MA, 1113 
Guibal F (1987) Dendrochronology of oak in Brittany. Dendrochronologia 5, 69-77

Hammer CU, Clausen HB, Dansgaard W (1980) Greenland ice sheet evidence of post-glacial volcanism and its climatic impact. Nature (Lond) 288, 230-235

Hillam J, Morgan RA, Tyers I (1987) Sapwood estimates and the dating of short ring sequences. In: Applications of Tree-Ring Studies: Current Research in Dendrochronology and Related Subjects (RGW Ward, ed), British Archaeological Reports International Series, 161-185

Hollstein E (1980) Mitteleuropaeische Eichenchronologie. Trierer dendrochronologische Forschungen zur Archaeologie und Kunstgeschichte. In: Trier Grabungen und Forschungen. Mainz am Rhein, Verlag Philipp von Zabern, 273

LaMarche VC, Hirschboeck KK (1984) Frost rings in trees as records of major volcanic eruptions. Nature (Lond) 307, 121-128

LaMarche VC, Graybill, DA, Fritts HC, Rose MR (1984) Increasing atmospheric carbon dioxide: tree ring evidence for growth enhancement in natural vegetation. Science 225, 1019-1021

Leuschner HH, Delorme A, Hoefle HC (1987) Dendrochronological study of oak trunks found in bogs of northwest Germany. in: Proceedings of the International Symposium on Ecological Aspects of TreeRing Analysis (GC Jacoby Jr, JW Hornbeck, eds), US Department of Energy, 298-318
Pilcher JR (1990) Sample preparation, cross-dating, and measurement. In: Methods of Dendrochronology: Applications in the Environmental Sciences (LA Kairiukstis, ER Cook, eds), International Institute for Applied Systems Analysis, Kluwer Academic Publishers, Boston, MA, 40-51

Pilcher JR, Munro MAR (1987) Long composite chronologies as indicators of background variations in tree growth. In: Methods of Dendrochronology. I. Proceedings of the Task Force Meeting on Methodology of Dendrochronology: EastWest Approaches ( $L$ Kairiukstis, Z Bednarz, E Feliksik, eds), Polish Academy of Sciences, Systems Research Institute, Warsaw, 117-124

Pilcher JR, Baillie MGL, Schmidt B, Becker B (1984) A 72-year tree-ring chronology for western Europe. Nature 312, 150-152

Pilcher JR, Baillie MGL, Brown DM, McCormac FG, McSweeney PB, McLawrence AS (1995) Dendrochronology of sub-fossil pine in the north of Ireland. $J$ Ecol $83,665-671$

Robinson WJ (1990) Dendrochronology in western North America: the early years. In: Methods of Dendrochronology: Applications in the Environmental Sciences (LA Kairiukstis, ER Cook, eds), International Institute for Applied Systems Analysis, Kluwer Academic Publishers, Boston, MA, 1-8

Schweingruber FH (1993) Trees and Wood in Dendrochronology. Springer-Verlag, Berlin 